\section{JEWELS IN THE IMPLANT CROWN}

Visitors to Stand D26 will be able to see three jewels from Trycare - the ADIN Implant System, the Estelite and the Sterisil Straw.

The ADIN Implant System is the new era in ethical implantology. Independently judged to be one of the most effective implants evaluated by New York University, ADIN implants are available from as little as $£ 125$ plus VAT including the implant, healing abutment, analogue, transfer and cement retained abutment.

Estelite is the jewel of composites. In addition to superb aesthetics, the ideal composite must have outstanding physical properties that deliver reliable, longlasting restorations simply and effectively. Tokuyama has developed such a composite.

The uniqueness of Estelite is achieved by combining a size and shape controlled spherical filler with an innovative polymerisation process that ensures rapid, controlled cure with no shade change after polymerisation. All of this with easy aesthetic perfection and remarkable handling.

The Sterisil

Straw and antimicrobial bottle system transforms waterline disinfection from a daily or hourly procedure into a simple annual event. Working night and day for 365 days, Sterisil Straw disinfects the dental unit's water lines providing safe and clean water throughout the year.

For further information visit stand D26, ask your local Trycare Representative or visit www. trycare.co.uk.

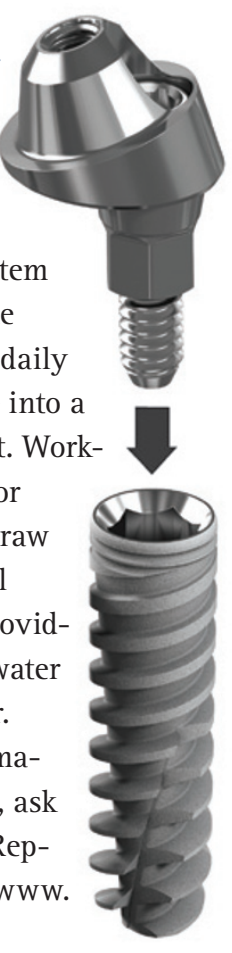

\section{COMPRESSED AIR AND SUCTION}

Cattani's Power Station is a quiet solution that houses both vacuum and compressed air requirements for up to six surgeries (four running simultaneously). This system uses inverter drive technology, which keeps power consumption at a minimum.

Cattani's suction systems are hand-built and produce high performance at affordable prices.
They are supplied with a three-year warranty on all major components. Cattani have a full range of suction systems ranging from single surgery to complete custom built modular units for hospitals, meaning that there is a system to suit the requirements of your clinic. Cattani Turbo-Jet 1 suction units are supplied with a two-year warranty.

Cattani oil-less compressors are renowned throughout the industry for their performance and reliability. Cattani compressors are supplied with a five-year warranty on all major components. Cattani have a full range of oil-less compressors, from single surgery to bespoke systems for hospitals. Cattani Aria compressors are fully HTM compliant.

\section{ENHANCE YOUR ORTHODONTIC SKILL-SET}

The Intelligent Alignment System comprises the Inman Aligner, Clear Smile and Six Month Braces - a one-stopshop for appropriate GDP orthodontics, taught and supported by the leading international short-termortho educators.

The Inman Aligner team has joined forces with the world's best educator for short-term fixed orthodontics, Dr Rick De Paul, to offer ethical training with treatments planned digitally and supported through linked forums. They are also offering 'ClearSmile', a new clear aligner system that facilitates control of a case with arch planning, with training to ensure you get the best out of the system.

Exhibiting at Showcase, the team behind the Inman Aligner will be available to show you exactly what these appliances could do for you and your patients.

If you want to find out more about adding Intelligent Alignment Systems to your skill-set, visit stand Q10 at BDTA Dental Showcase 2013.

\section{YOU'D BE LOOPY NOT TO TRY THESE}

Consider yourself to be one of the 53-82\% of dental professionals who suffer from musculo-skeletal complaints, or think you're on the way to being one? Then you need to stop by Evident stand L04a where their team of experienced consultants can demonstrate how loupes and a light could benefit you, whilst also providing expert posture advice.

Evident have been providing dental loupes and lights to the UK market for over 20 years, always taking into consideration complete comfort and perfect vision. Recently, the team has taken this commitment one step further by undergoing theoretical and practical training to understand even more about the ideal working position.

Evident's impressive range of ExamVision loupes have been specifically designed to allow the 'ideal posture' to be attained - something which not all loupes can achieve - and are custom-made to meet the highest standards of quality, comfort and performance. So now, when you visit Evident stand L04a your loupe

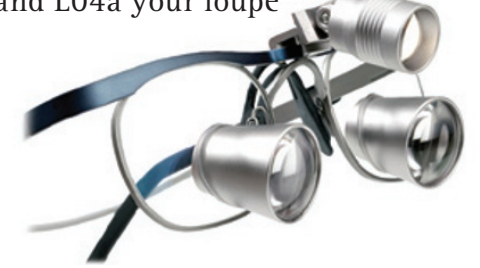

and light demonstration will also include FREE posture analysis and advice so that you can work in long-term comfort within the known parameters of body positioning.

Simply visit stand L04a at BDTA Dental Showcase 2013. Or, Freephone 0500321111 or visit www.examvision.co.uk to request a no-obligation demonstration.

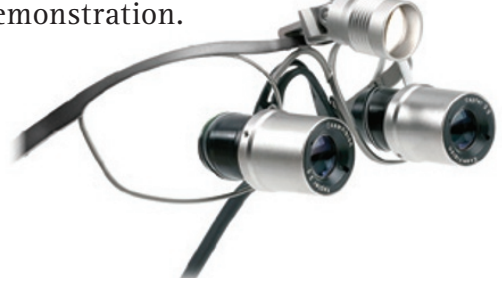

